\title{
COMPORTAMENTO DO CONSUMIDOR NOS EnANPADs: UM LEVANTAMENTO BIBLIOMÉTRICO SOBRE AS METODOLOGIAS EMPREGADAS
}

André Luis Faria DUARTE ${ }^{1}$

Emiliano Carlos Serpa CASTOR ${ }^{2}$

Luiz Antônio RAMOS NETO ${ }^{3}$

Nuno Alvares FELIZARDO JÚNIOR ${ }^{4}$

Irene Raguenet TROCCOLI ${ }^{5}$

\begin{abstract}
${ }^{1}$ Mestrado em Administração e Desenvolvimento Empresarial (MADE), UNESA. alduarte@cnen.gov.br
${ }^{2}$ Mestrado em Administração e Desenvolvimento Empresarial (MADE), UNESA. emiliano.castor@gmail.com

${ }^{3}$ Mestrado em Administração e Desenvolvimento Empresarial (MADE), UNESA. luiz.ar.neto@gmail.com

${ }^{4}$ Mestrado em Administração e Desenvolvimento Empresarial (MADE), UNESA. nuno.felizardojr@gmail.com

${ }^{5}$ Mestrado em Administração e Desenvolvimento Empresarial (MADE), UNESA. irene.troccoli@estacio.br
\end{abstract}

Recebido em: 15/07/2015 - Aprovado em: 11/01/2016 - Disponibilizado em: 30/07/2016

\begin{abstract}
Resumo - A busca incessante pelo entendimento dos hábitos de consumo vem-se tornando cada dia mais relevante aos profissionais de Marketing. Isto porque, no entendimento desta disciplina, as empresas existem para satisfazer as necessidades dos consumidores, as quais só podem ser completamente saciadas quando os profissionais da área de Marketing conseguem identificar o que os clientes estão buscando. Não conhecer os clientes pode se tornar o maior problema de uma organização; entender o que realmente querem os consumidores é ponto-chave para o êxito das empresas. Este levantamento bibliométrico mapeou as abordagens, as finalidades, os meios, as técnicas de coleta de dados e de levantamento de informações, e as técnicas de tratamento dos dados e das evidências dos artigos veiculados na subárea de Comportamento do Consumidor dentro da área de Marketing dos EnANPADs do triênio 2010-12. Tipicamente, o artigo desta amostra apresenta abordagem quantitativa, tem finalidade exploratória, utiliza o meio survey, obtém dados por meio de questionário, e os trata usando análise fatorial. Ao final, considerações são feitas e futuros estudos são sugeridos.
\end{abstract}

Palavras-chave - Comportamento do consumidor; metodologia; bibliometria

\begin{abstract}
Understanding consumer behavior is becoming increasingly relevant to marketers, because this helps companies to meet the needs of consumers, which can only occur when marketers know what customers want. As a consequence, consumer behavior constantly draws the attention of these professionals, since they are responsible for understanding and influencing individuals' consumption. This bibliometric survey mapped the approaches, goals, means, data collection and information gathering techniques, and data and evidence processing techniques of the Consumer Behavior articles of the EnANPADs during years 2010 to 2012. Typically, such an article has a quantitative approach, is exploratory, uses survey, has its data obtained through a questionnaire, and uses factor analysis. Finally, considerations are made and future studies are suggested.
\end{abstract}

Key words - Consumer behavior; methodology; bibliometrics

\section{INTRODUÇÃO}

Com o dinamismo no mundo atual, conforme Sheth, Mittal e Newman (2001) e alguns fatores são primordiais para a Kotler e Keller (2012): entender o que sobrevivência e para a busca de espaço no realmente querem os consumidores, e mercado. Não conhecer os clientes pode se monitorá-los de forma a compreender como tornar o maior problema de uma organização, eles criam seus processos de tomada de 
decisão de compra e de uso do produto, são pontos-chave para o êxito das empresas.

O estudo científico do comportamento do consumidor surgiu na década de 1960, por meio da influência de autores como Ferber (1958), Katona (1960), Howard (1963), Newman (1963) e Engel (1968), que estudavam as variáveis que afetavam a escolha do consumidor e o motivo de estas ações não se repetirem em compras de mesmas características ou de produtos diferentes. Conforme cresceu em importância e em espaço, esta vertente de pesquisa passou a ganhar espaço em programas de mestrado e de doutorado ao redor do mundo (HOLBROOK, 1987).

A busca incessante pelo entendimento dos hábitos de consumo vem-se tornando cada dia mais relevante aos profissionais de Marketing. Isto porque, no entendimento desta disciplina, as empresas existem para satisfazer as necessidades dos consumidores, as quais só podem ser completamente saciadas quando os profissionais da área de Marketing conseguem identificar o que os clientes estão buscando (SOLOMON, 2002). Nesse sentido, o comportamento do consumidor é alvo constante da atenção destes profissionais, uma vez que são eles os responsáveis por entender e por influenciar os indivíduos ao consumo e à busca pelo ter.

Mas, ao mesmo tempo em que a importância por este tema é evidente, surge uma questão: aqueles pesquisadores acadêmicos que por ele se interessam o fazem por meio da adoção de qual metodologia? Esta pergunta é legítima, porquanto se sabe que a opção pela adoção de métodos de pesquisa específicos guarda em si uma proposta científica:

No que diz respeito ao processo da pesquisa, cabe destacar que não se trata de uma mera classificação, mas sim um fruto do paradigma através do qual o pesquisador desenvolve seus estudos. (...) No entender de Collis e Hussey (2005), as crenças básicas sobre o mundo acabam sendo refletidas na maneira como o pesquisador projeta sua pesquisa, coleta e analisa seus dados e como redige seu trabalho. Para esses autores é importante reconhecer e entender o paradigma pessoal, pois ele vai determinar todo o transcurso de seu projeto de pesquisa. (COELHO; SILVA, 2007, p. 143).

Portanto, a proposta do presente artigo, bibliométrico de abordagem quantitativa, é mapear os perfis metodológicos dos artigos aprovados no triênio 2010-12 na subárea Comportamento do Consumidor dos Encontros da Associação Nacional de PósGraduação e Pesquisa em Administração (EnANPADs).

A opção por este evento se deve a ele ser o mais importante, no Brasil, na área de Administração de Empresas. Sua promoção se dá anualmente pela Associação Nacional de Pós-Graduação e Pesquisa em Administração (ANPAD): contando atualmente com 77 programas de pós-graduação stricto sensu efetivamente associados, a entidade foi criada em meados da década de 1970, a partir da iniciativa dos oito programas de pósgraduação então existentes no Brasil. No 
momento configura-se como “(...) o principal órgão de interação entre programas associados, grupos de pesquisa da área e a comunidade internacional" (ANPAD, 2013, sem página definida). Anualmente, a ANPAD promove espaços de intercâmbio entre professores, pesquisadores e estudantes através de vários eventos acadêmicos, de suas diversas instâncias.

O presente artigo está dividido em quatro partes, além desta introdução: referencial teórico, metodologia utilizada, análise dos resultados e conclusão.

\section{REFERENCIAL TEÓRICO - COMPORTAMENTO DO CONSUMIDOR}

Kotler e Keller (2012, p. 164) definem comportamento do consumidor como "O estudo de como os indivíduos, grupos e organizações selecionam, compram, usam e descartam bens, serviços, ideias ou experiências para satisfazer suas necessidades e desejos". Para Engel, Blackwell e Miniard (2000, p. 4) trata-se das "atividades diretamente ligadas à obtenção, consumo e disposição de produtos e serviços, incluindo os processos decisórios que antecedem e sucedem a estas ações".

Alguns autores esclarecem que o processo de tomada de decisão de compra do consumidor é influenciado por fatores internos e externos (ENGEL; BLACKWELL; MINIARD，2000; CHURCHILL; PETER,
2000; SCHIFFMAN; KANUK, 2000; SOLOMON, 2002; KOTLER; KELLER, 2012), no que são complementados por Churchill e Peter (2000, p. 160), que ressaltam a existência de influências sociais e situacionais, tais como aquelas advindas dos chamados grupos de referência, “(...) grupos de pessoas que influenciam os pensamentos, os sentimentos e os comportamentos do consumidor".

Por seu turno, Engel, Blackwell e Miniard (2000) observam outros elementos interferindo na tomada de decisão do consumidor - influências ambientais, diferenças individuais e fatores pessoais enquanto Solomon (2002) e Schiffman e Kanuk (2000) compreendem que, além das interferências pessoais e sociais, existem influências psicológicas e culturais.

Vale notar que Kotler e Keller (2012) propuseram modelo onde fatores psicodinâmicos internos e externos influenciam os hábitos do consumidor, esclarecendo que “(...) os fatores culturais exercem a maior e mais profunda influência sobre o comportamento do consumidor" ( $p$. 164).

Também para Dias (2004) a cultura traz valores e crenças entre gerações, influenciando o comportamento do indivíduo. Já as subculturas, segundo Kotler e Keller (2012, p. 165) “(...) são um foco em pessoas de uma mesma cultura, por exemplo, nacionalidade, religiões, grupos raciais e 
regiões geográficas". Dessa forma, Dias (2004) acredita que o Marketing tem uma oportunidade de estudo comportamental, pois estas subculturas, ao crescerem, se tornam influentes para o comportamento de compra.

Ainda dentro do modelo de Kotler e Keller (2012), o comportamento do consumidor sofre influência de fatores sociais, entendidos como família, grupos de referência e posição social: "O comportamento do ser humano é baseado na aprendizagem propiciada pela interação social entre as pessoas" (DIAS, 2004, p. 59).

Estes grupos de afinidade, por sua vez, se dividem em dois subgrupos (KOTLER; KELLER, 2012, p. 165): 1) primários: “a família, amigos, vizinhos e colegas de trabalho, com os quais se interage de modo contínuo e forma”, e 2) secundários: “grupos religiosos e profissionais ou associações de classe, que costumam ser mais formais e exigir menos interação contínua". Este aspecto social pode ser observado nos tipos de renda e de moradia, assim como no status profissional, pois “(...) a associação com a classe social é um determinante mais significativo do que o valor da renda" (SANDHUSEN, 2003, p.162).

O terceiro tipo de fator no modelo de Kotler e Keller (2012) são os pessoais, com idade e estágio de vida, ocupação e circunstâncias econômicas, personalidade e autoimagem, estilo de vida e valores participando do perfil da ação do consumidor.
Vai daí que, entendendo a influência destas características sobre o comportamento de compra do consumidor, o mercado pode apresentar vários produtos que têm suas propriedades voltadas para atender a idade e ao ciclo de vida familiar (DIAS, 2004).

No que diz respeito aos fatores psicológicos que influenciam as escolhas dos consumidores, Kotler e Keller (2012) apresentam cinco instâncias que participam da ação da compra: motivação, percepção, aprendizagem, emoções e memória: 1) a motivação é “(...) uma necessidade (que) passa a ser um motivo quando alcança um nível de intensidade suficiente para levar uma pessoa a agir" (KOTLER; KELLER, 2012, p. 173); b) a percepção, conforme Dias (2004), é um processo no qual as pessoas passam para compreender o mundo, analisando e reconhecendo situações; 3) a aprendizagem é considerada, por Gianesi e Corrêa (2006), como experiência pela qual as pessoas passam ao longo da vida, cujas marcas podem, ou não, influenciar suas decisões; 4) emoções, segundo Kotler e Keller (2012, p. 176), explicam que o consumidor não tem reações sempre racionais, pois um tipo de marca ou produto pode fazer o consumidor experimentar vários tipos de emoções, dentre elas orgulho, animação ou confiança; e 5) a memória está inclusa nos estudos sob duas formas, segundo Kotler e Keller (2012, p. 176): memória de "curto prazo - um repositório temporário e limitado de 
informações - e longo prazo - um repositório mais permanente e essencialmente ilimitado".

Contudo, apenas compreender os fatores que influenciam o comportamento do consumidor pode não ser suficiente para o desenho de estratégias de Marketing bem sucedidas, de acordo com Kotler e Keller (2012): também é necessário compreender como se desenrola o processo de decisão de compra.

Para isto, estes autores propõem uma descrição processual, composta de cinco estágios (ver Figura 1). No caso, o primeiro passo consiste no reconhecimento de uma necessidade de consumo por parte do indivíduo, o qual em seguida busca informações a respeito. Na terceira fase, ele avalia as alternativas de que dispõe, para, em seguida, tomar a decisão de compra. Finalmente, o consumidor realiza um retrospecto deste processo, definidor do seu comportamento pós-compra.

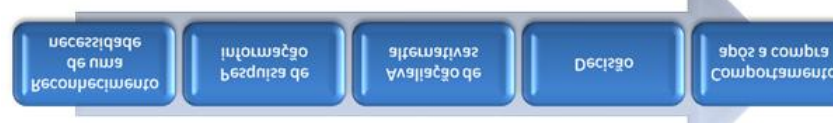

Figura 1 - Processo de decisão de compra: o modelo de cinco estágios

Fonte: Morais (2013)

\section{MÉTODO}

Este levantamento bibliométrico mapeou as características específicas sobre a metodologia aplicada em trabalhos aprovados no triênio 2010-12 na subárea Comportamento do Consumidor dos
EnANPADs. Isto implica que sua abordagem é quantitativa, sendo estatístico quanto aos meios e descritivo quanto aos fins.

Foram estudados cinco aspectos da amostra de artigos levantada: tipo de abordagem, finalidade da pesquisa, meios da pesquisa, técnicas de levantamento dos dados ou das evidências, e formas de análise dos dados e das evidências. Vale lembrar que, à exceção do tipo de abordagem - que se configura tão somente de três maneiras: qualitativa, quantitativa e quali-quanti (MICHEL, 2009) - as demais classificações podem ser de diversas ordens, inclusive mesclando duas ou mais classificações, conforme o intuito da pesquisa (MICHEL, 2009; GIL, 2012; CERVO; BERVIAN; DA SILVA, 2013).

Para se atingir o objetivo desta pesquisa, inicialmente acessou-se o site da ANPAD (ANPAD, 2013), onde foi buscada a área reservada aos EnANPADs. Ali foram localizados, dentre todos os trabalhos da Divisão Acadêmica Marketing do triênio em questão, aqueles concentrados especificamente na subárea Comportamento do Consumidor, e que somaram 72 trabalhos. Estes foram impressos e lidos, assim como foram utilizados os respectivos anais para o levantamento de informações complementares que eventualmente se fizessem necessárias.

A referida leitura visou a apreender, da amostra, as informações relativas à metodologia seguida pelos autores dos 
artigos, especificamente no que diz respeito a seis aspectos: abordagem, método científico, meio técnico de investigação, finalidade, forma de levantamento dos dados ou das evidências, e técnica de análise dos dados ou das evidências.

É importante frisar que, ao longo deste esforço, não se fez nenhuma inferência a respeito das características de cada artigo pesquisado no caso de a informação visada ali não se encontrar claramente disponível. E porque só constam nas tabelas as especificações que foram informadas pelos respectivos autores, é de se supor que, na amostra dos 72 artigos, tenham sido utilizados muito mais métodos científicos, meios técnicos de investigação, finalidades, formas de levantamento dos dados ou das evidências, e técnicas de análise dos dados ou das evidências do que os informados neste levantamento bibliométrico.

As informações assim coletadas foram transpostas para planilha Excel e analisadas, confeccionando-se, para tanto, quadros, tabelas e gráficos que tornassem a visualização mais prática. Em seguida, os dados foram interpretados.

\subsection{BIBLIOMETRIA}

A bibliometria não é um meio de pesquisa acadêmica, mas sim “(...) um conjunto de leis e princípios empíricos que contribuem para estabelecer os fundamentos teóricos da Ciência da Informação" (GUEDES; BORSHIVER， 2005， p. 2).
Pritchard (1969) entende a bibliometria como um recurso, cuja utilidade é a quantificação dos processos de comunicação escrita. Já para Araújo (2006, p.12) é uma

(...) técnica quantitativa e estatística de medição dos índices de produção e disseminação do conhecimento científico (...) consistindo na aplicação de técnicas estatísticas e matemáticas para descrever aspectos da literatura e de outros meios de comunicação (análise quantitativa da informação).

De acordo com Figueiredo (1977), “a bibliometria desde sua origem é marcada por uma dupla preocupação: a análise da produção científica e a busca de benefícios práticos imediatos para bibliotecas (desenvolvimento de coleções, gestão de serviços bibliotecários)". O controle bibliográfico, no sentido de se conhecer o tamanho e as características dos acervos e elaborar previsões de crescimento, é destacado como objetivo "mais óbvio" da bibliometria (NICHOLAS; RITCHIE, 1978, p. 12).

Em seu princípio, os estudos bibliométricos visavam à medição de livros, levantando as quantidades de edições e exemplares, o número de palavras etc. Ao longo do tempo, a técnica foi se aperfeiçoando e se voltando para o estudo de novos formatos de produção bibliográfica, como artigos de periódicos e outros tipos de documentos, encaminhando estudos para a produtividade de autores e do estudo de citações. 
Sendo assim, quando a biblometria é utilizada para mapeamento de artigos, consegue-se ter de forma precisa a capacidade intelectual de um país. E seus resultados são objeto de estudos de estudantes, professores, pesquisadores. Figueiredo (1977) destaca que a bibliometria é marcada por dois aspectos: a análise da produção científica, e a busca de benefícios práticos imediatos para bibliotecas e para a promoção do controle bibliográfico.

\section{ANÁLISE DOS RESULTADOS}

A amostra de 72 artigos dividiu-se em 20, 28 e 24 artigos respectivamente para os anos de 2010 a 2012, indicando relativo equilíbrio na distribuição dos eventos.

Passando-se aos resultados relativos às opções metodológicas, iniciando-se com as abordagens, tem-se o seguinte para o triênio (ver Tabela 1): 1) mais de metade da amostra não informou explicitamente qual a abordagem utilizada; 2) dentre o restante, $50 \%$ da preferência recaiu sobre a abordagem quantitativa, praticamente o dobro daquela verificada junto à qualitativa; 3) a abordagem quali-quanti teve nível de preferência pouco maior do que a qualitativa.

O mesmo exame feito ano a ano trouxe as seguintes indicações (ver Tabela 1): 1) o ano de 2010 foi aquele em que a abordagem quantitativa foi preferida; 2) o ano de 2011 foi aquele em que as abordagens qualitativa e quali-quanti foram mais utilizadas; 3) em todos os anos, o percentual de falta destas informações não apresentou grandes variações; e 4) os três tipos de abordagem sofreram variações erráticas ao longo dos anos, sem nenhum tipo de tendência (de alta ou de baixa) definida.

\begin{tabular}{|c|c|c|c|c|c|c|c|c|}
\hline \multirow{3}{*}{ Abordagem } & \multicolumn{8}{|c|}{ ANOS } \\
\hline & \multicolumn{2}{|c|}{2010} & \multicolumn{2}{|c|}{2011} & \multicolumn{2}{|c|}{2012} & \multicolumn{2}{|r|}{$2010-12$} \\
\hline & Total & $\%$ no ano & Total & $\%$ no ano & Total & $\%$ no ano & Total & \% no período \\
\hline Qualitativa & 1 & $10,0 \%$ & 4 & $33,3 \%$ & 3 & $25,0 \%$ & 8 & $23,5 \%$ \\
\hline Quantitativa & 7 & $70,0 \%$ & 3 & $25,0 \%$ & 7 & $58,3 \%$ & 17 & $50,0 \%$ \\
\hline Quali-Quanti & 2 & $20,0 \%$ & 5 & $41,7 \%$ & 2 & $16,7 \%$ & 9 & $26,5 \%$ \\
\hline Total dos informados & 10 & $100 \%$ & 12 & $100 \%$ & 12 & $100 \%$ & 34 & $100 \%$ \\
\hline Não Informado & 10 & & 16 & & 12 & & 38 & \\
\hline
\end{tabular}

Fonte: Elaboração própria

Quando passou à classificação dos artigos quanto à finalidade e aos meios de pesquisa, assim como quanto à técnica utilizada para o levantamento de dados ou análise das evidências, este levantamento bibliométrico deixou de relacionar estas informações ao número de artigos que a trouxeram. Isto porque, contrariamente ao que acontece no caso da abordagem metodológica (que só pode se enquadrar em uma das três qualificações indicadas na Tabela 1), não é incomum que os pesquisadores trabalhem, em uma mesma investigação, com mais do que 
apenas uma finalidade, de um meio e até mesmo de uma técnica.

Assim, o que se fez aqui foi tão somente identificar os tipos utilizados pelos autores e os respectivos números de vezes em que tais informações foram fornecidas na amostra como um todo, sem a preocupação de se quantificar as parcelas da amostra em que elas estavam e não estavam disponíveis.

Portanto, na amostra dos 72 artigos foram identificados cinco tipos de finalidade: descritiva, quase ou pré-experimental, experimental, exploratória e explicativa, com um total de 37 citações (ver Tabela 2). Ano a ano o que se viu foi o seguinte: a) em 2010, não houve pesquisas explicativas, e a preferência ficou com os estudos descritivos (cerca de $36 \%$ do total), enquanto os experimentais e os exploratórios somaram quase $60 \%$ da preferência do ano; b) em 2011, só houve pesquisas descritivas e exploratórias, sendo que estas últimas chegaram a praticamente $54 \%$ do total; e c) em 2012, houve a maior diversidade de finalidades de pesquisa, com todos os cinco tipos tendo sido contemplados, muito embora a preferência tenha sido francamente a favor das exploratórias, com pouco mais de $30 \%$ do total.

Já para o triênio como um todo, a vantagem ficou claramente com as pesquisas exploratórias, cuja preferência alcançou pouco mais de $40 \%$, seguida da descritiva, com praticamente $30 \%$ (ver Tabela 2). Vale notar que tanto a explicativa quanto a quase ou pré-experimental não chegaram a, conjuntamente, alcançar nem $10 \%$ das preferências.

Tabela 2 - Enanpads 2010 a 2012 - Artigos da subárea Comportamento do Consumidor, da área de Marketing - Finalidade da pesquisa

\begin{tabular}{|c|c|c|c|c|c|c|c|c|}
\hline \multirow[b]{2}{*}{ Finalidade } & \multicolumn{2}{|c|}{2010} & \multicolumn{2}{|c|}{2011} & \multicolumn{2}{|c|}{2012} & \multicolumn{2}{|c|}{ 2010-12 } \\
\hline & $\begin{array}{l}\text { Total de } \\
\text { menções }\end{array}$ & $\%$ no ano & $\begin{array}{l}\text { Total de } \\
\text { menções }\end{array}$ & $\%$ no ano & $\begin{array}{l}\text { Total de } \\
\text { menções }\end{array}$ & $\%$ no ano & $\begin{array}{l}\text { Total de } \\
\text { menções }\end{array}$ & $\%$ no periodo \\
\hline Descritiva & 5 & $35,7 \%$ & 3 & $23,1 \%$ & 3 & $18,8 \%$ & 11 & $29,7 \%$ \\
\hline Quase ou Pré-Experimental & 1 & $7,1 \%$ & 0 & $0,0 \%$ & 1 & $6,3 \%$ & 2 & $5,4 \%$ \\
\hline Experimental & 4 & $28,6 \%$ & 0 & $0,0 \%$ & 3 & $18,8 \%$ & 7 & $18,9 \%$ \\
\hline Exploratória & 4 & $28,6 \%$ & 7 & $53,8 \%$ & 5 & $31,3 \%$ & 16 & $43,2 \%$ \\
\hline Explicativa & 0 & $0 \%$ & 0 & $0 \%$ & 1 & $6,3 \%$ & 1 & $2,7 \%$ \\
\hline TOTAL & 14 & $100 \%$ & 10 & $100 \%$ & 13 & $100 \%$ & 37 & $100 \%$ \\
\hline
\end{tabular}

Fonte: Elaboração própria

A classificação dos artigos quanto aos meios da pesquisa mostrou que os utilizados foram survey, o bibliográfico, o bibliométrico, o netnográfico e a pesquisa de campo, com um total de 30 menções na amostra (ver Tabela 3). No triênio como um todo, a preferência ficou com o primeiro, acusando pouco mais de $73 \%$. Em segundo lugar ficou o meio bibliográfico, com $13,3 \%$, e os três outros tiveram participações marginais.

A análise anual mostrou que apenas em 2011 foram usados todos os cinco meios identificados. Em 2010, o uso da survey dividiu espaço com o meio bibliográfico, embora de forma francamente favorável ao primeiro, que, por sua vez, ocupou todas as atenções no ano de 2012 (ver Tabela 3). 
Tabela 3 - Enanpads 2010 a 2012 - Artigos da subárea Comportamento do Consumidor, da área de Marketing - Meios da pesquisa

\begin{tabular}{|c|c|c|c|c|c|c|c|c|}
\hline \multirow[b]{2}{*}{ Meios de Pesquisa } & \multicolumn{2}{|c|}{2010} & \multicolumn{2}{|c|}{2011} & \multicolumn{2}{|c|}{2012} & \multicolumn{2}{|c|}{ 2010-12 } \\
\hline & $\begin{array}{l}\text { Total de } \\
\text { menções }\end{array}$ & $\%$ no ano & \begin{tabular}{|c|} 
Total de \\
menções
\end{tabular} & $\%$ no ano & \begin{tabular}{|c|} 
Total de \\
menções
\end{tabular} & $\%$ no ano & $\begin{array}{l}\text { Total de } \\
\text { menções }\end{array}$ & $\%$ no periodo \\
\hline Survey & 8 & $88,9 \%$ & 8 & $53,3 \%$ & 6 & $100 \%$ & 22 & $73,3 \%$ \\
\hline Bibliográfico & 1 & $11,1 \%$ & 3 & $20,0 \%$ & 0 & $0 \%$ & 4 & $13,3 \%$ \\
\hline Bibliométrica & 0 & $0 \%$ & 1 & $6,7 \%$ & 0 & $0 \%$ & 1 & $3,3 \%$ \\
\hline Netnográfica & 0 & $0 \%$ & 1 & $6,7 \%$ & 0 & $0 \%$ & 1 & $3,3 \%$ \\
\hline Pesquisa de campo & 0 & $0 \%$ & 2 & $13,3 \%$ & 0 & $0 \%$ & 2 & $6,7 \%$ \\
\hline TOTAL & 9 & $100 \%$ & 15 & $100 \%$ & 6 & $100 \%$ & 30 & $100 \%$ \\
\hline
\end{tabular}

Fonte: Elaboração própria

Foram identificados seis tipos de técnicas de coleta de dados e de levantamento de informações, com 78 citações na amostra: documental, entrevista, observação (participante ou não), questionário, técnica projetiva e grupo focal (ver Tabela 4).

No triênio como um todo, o questionário foi a técnica mais utilizada, com quase $62 \%$ das menções. Em segundo lugar posicionou-se a entrevista, e as demais técnicas tiveram uso marginal. A ressaltar apenas que apenas no ano de 2011 o questionário perdeu um pouco de ímpeto, ficando sua preferência abaixo dos $50 \%$, ao mesmo tempo em que se expandiam a entrevista, a observação e o grupo focal.

Tabela 4 - Enanpads 2010 a 2012 - Artigos da subárea Comportamento do Consumidor, da área de Marketing - Técnicas de levantamento de dados ou de evidências

\begin{tabular}{|c|c|c|c|c|c|c|c|c|}
\hline \multirow{2}{*}{$\begin{array}{c}\text { Técnica de levantamento de dados ou de } \\
\text { evidências }\end{array}$} & \multicolumn{2}{|c|}{2010} & \multicolumn{2}{|c|}{2011} & \multicolumn{2}{|c|}{2012} & \multicolumn{2}{|c|}{ 2010-12 } \\
\hline & $\begin{array}{l}\text { Total de } \\
\text { menções }\end{array}$ & $\%$ no ano & $\begin{array}{l}\text { Total de } \\
\text { menções }\end{array}$ & $\%$ no ano & $\begin{array}{l}\text { Total de } \\
\text { menções }\end{array}$ & $\%$ no ano & $\begin{array}{l}\text { Total de } \\
\text { menções }\end{array}$ & $\%$ no periodo \\
\hline Entrevista & 3 & $13,6 \%$ & 11 & $35,5 \%$ & 4 & $16,0 \%$ & 18 & $23,1 \%$ \\
\hline Observação (participante ou não) & 1 & $4,5 \%$ & 2 & $6,5 \%$ & 1 & $4,0 \%$ & 4 & $5,1 \%$ \\
\hline Questionário & 17 & $77,3 \%$ & 15 & $48,4 \%$ & 16 & $64,0 \%$ & 48 & $61,5 \%$ \\
\hline Técnica projetiva & 0 & $0 \%$ & 0 & $0 \%$ & 1 & $4,0 \%$ & 1 & $1,3 \%$ \\
\hline Grupo focal & 1 & $4,5 \%$ & 3 & $9,7 \%$ & 2 & $8,0 \%$ & 6 & $7,7 \%$ \\
\hline Documental & 0 & $0 \%$ & 0 & $0 \%$ & 1 & $4,0 \%$ & 1 & $1,3 \%$ \\
\hline TOTAL & 22 & $100 \%$ & 31 & $100 \%$ & 25 & $100 \%$ & 78 & $100 \%$ \\
\hline
\end{tabular}

Fonte: Elaboração própria

Finalmente, no que diz respeito às formas de análise dos dados ou das evidências, foram identificadas 20 delas, citadas 104 vezes na amostra estudada. Delas, apenas duas referentes à abordagem qualitativa: análises de conteúdo e de discurso (ver Tabela 5). As mais praticadas no triênio foram a análise fatorial e a modelagem de equações estruturais, responsabilizando-se conjuntamente por $45 \%$ do resultado total da pesquisa. Seguiu-se a análise de variância, com quase $10 \%$ das observações. Depois, o destaque ficou com a análise de conteúdo, com quase $8 \%$ das observações, e com a análise de clusters, com quase $7 \%$.

Ano a ano, a análise mostra que o padrão do triênio se repetiu em 2010 e em 2011 no que tange às duas técnicas mais praticadas: análise fatorial e a modelagem de equações estruturais. Já em 2012, a modelagem perdeu em preferência para a análise de variância (ver Tabela 5). 


\begin{tabular}{|c|c|c|c|c|c|c|c|c|}
\hline \multicolumn{9}{|c|}{ 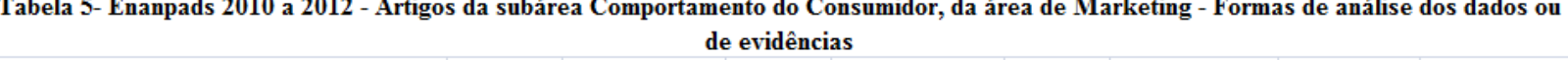 } \\
\hline \multirow{2}{*}{$\begin{array}{c}\text { Formas de análise dos dados ou de } \\
\text { evidências }\end{array}$} & \multicolumn{2}{|c|}{2010} & \multicolumn{2}{|c|}{2011} & \multicolumn{2}{|c|}{2012} & \multicolumn{2}{|c|}{ 2010-12 } \\
\hline & $\begin{array}{l}\text { Total de } \\
\text { menções }\end{array}$ & $\%$ no ano & $\begin{array}{l}\text { Total de } \\
\text { menções }\end{array}$ & $\%$ no ano & $\begin{array}{r}\text { Total de } \\
\text { menções }\end{array}$ & $\%$ no ano & $\begin{array}{l}\text { Total de } \\
\text { menções }\end{array}$ & $\%$ no periodo \\
\hline Análise de variância & 4 & $13,8 \%$ & 1 & $2,6 \%$ & 5 & $13,9 \%$ & 10 & $9,6 \%$ \\
\hline Análise fatorial & 10 & $34,5 \%$ & 11 & $28,2 \%$ & 9 & $25,0 \%$ & 30 & $28,8 \%$ \\
\hline Análise de correlação & 1 & $3,4 \%$ & 0 & $0 \%$ & 0 & $0 \%$ & 1 & $1,0 \%$ \\
\hline Estatistica descritiva & 1 & $3,4 \%$ & 1 & $2,6 \%$ & 4 & $11,1 \%$ & 6 & $5,8 \%$ \\
\hline Modelagem de equações estruturais & 7 & $24,1 \%$ & 6 & $15,4 \%$ & 4 & $11,1 \%$ & 17 & $16,3 \%$ \\
\hline Modelos logisticos multivariados binomiais & 1 & $3,4 \%$ & 0 & $0 \%$ & 0 & $0 \%$ & 1 & $1,0 \%$ \\
\hline Teste de qui-quadrado & 2 & $6,9 \%$ & 0 & $0 \%$ & 0 & $0 \%$ & 2 & $1,9 \%$ \\
\hline Regressão & 0 & $0 \%$ & 2 & $5,1 \%$ & 1 & $2,8 \%$ & 3 & $2,9 \%$ \\
\hline Regressão logistica & 2 & $6,9 \%$ & 1 & $2,6 \%$ & 1 & $2,8 \%$ & 4 & $3,8 \%$ \\
\hline Análise discriminante & 0 & $0 \%$ & 2 & $5,1 \%$ & 1 & $2,8 \%$ & 3 & $2,9 \%$ \\
\hline Análise conjunta & 0 & $0 \%$ & 2 & $5,1 \%$ & 0 & $0 \%$ & 2 & $1,9 \%$ \\
\hline Análise de clusters & 0 & $0 \%$ & 4 & $10,3 \%$ & 3 & $8,3 \%$ & 7 & $6,7 \%$ \\
\hline Associação de padrões & 0 & $0 \%$ & 2 & $5,1 \%$ & 0 & $0 \%$ & 2 & $1,9 \%$ \\
\hline Minimos quadrados parciais & 0 & $0 \%$ & 0 & $0 \%$ & 1 & $2,8 \%$ & 1 & $1,0 \%$ \\
\hline Análise de covariância & 0 & $0 \%$ & 0 & $0 \%$ & 1 & $2,8 \%$ & 1 & $1,0 \%$ \\
\hline Teste de homogeneidade das variâncias & 0 & $0 \%$ & 0 & $0 \%$ & 1 & $2,8 \%$ & 1 & $1,0 \%$ \\
\hline Escalada & 0 & $0 \%$ & 1 & $2,6 \%$ & 1 & $2,8 \%$ & 2 & $1,9 \%$ \\
\hline Teste de normalidade & 0 & $0 \%$ & 0 & $0 \%$ & 1 & $2,8 \%$ & 1 & $1,0 \%$ \\
\hline Análise de conteúdo & 1 & $3,4 \%$ & 5 & $12,8 \%$ & 2 & $5,6 \%$ & 8 & $7,7 \%$ \\
\hline Análise do discurso & 0 & $0 \%$ & 1 & $2,6 \%$ & 1 & $2,8 \%$ & 2 & $1,9 \%$ \\
\hline TOTAL & 29 & $100 \%$ & 39 & $100 \%$ & 36 & $100 \%$ & 104 & $100 \%$ \\
\hline
\end{tabular}

Fonte: Elaboração própria

\section{CONSIDERAÇÕES FINAIS}

A primeira e mais importante consideração que se pode tirar deste levantamento remete à ressalva feita no item de metodologia, de que nenhuma inferência foi feita quando não se encontrava a informação buscada no artigo analisado.

O que se verificou, na prática, é que, por diversas vezes, esta lacuna existia. Exemplo é o resultado da Tabela 1: dos 72 artigos da amostra, 38 - ou seja, mais da metade - não informaram a abordagem adotada. Por mais que, pela leitura do material, fosse evidente se sua abordagem era qualitativa, quantitativa ou quali-quanti, o rigor científico exige que esta informação como tantas outras - seja formal e claramente fornecida ao leitor. Em princípio, esta lacuna indica que os autores nem sempre estão preocupados em dar este tipo de informação a seus leitores. Em seguida, isto também indica que os avaliadores dos EnANPADs igualmente não se mostram preocupados com esta lacuna.

Tal fato deve ser motivo de reflexão, porque a explicitação dos recursos metodológicos utilizados em trabalhos científicos tem dois propósitos. O primeiro é garantir o pleno entendimento da pesquisa, o que é fundamental para uma eventual crítica a seu respeito - o que, por sua vez, serve para a construção do pensamento científico, além de dar subsídios a outros pesquisadores que tenham interesse em desenvolver trabalhos paralelos.

A segunda consideração remete à primazia dos estudos puramente quantitativos encontrada na amostra estudada, com seus 
$50 \%$ identificados. Esta desvantagem à abordagem qualitativa é preocupante, tendo em vista que a produção de conhecimento em Marketing, quando alvo de críticas quanto à sua própria capacidade de ser útil enquanto área de conhecimento, normalmente vem acompanhado de reclamações quanto à suficiência das contribuições oferecidas por pesquisas qualitativas.

Por outro lado, é alvissareiro que 26,5\% da amostra tenha optado pela abordagem quali-quanti. Esta opção pode estar sinalizando o desejo dos pesquisadores em expandir o entendimento de uma abordagem à outra, para convergir ou para confirmar os resultados de diferentes fontes de dados, deixando transparecer a vontade de enriquecer os trabalhos científicos.

Da mesma forma, é surpreendente que a identificação das finalidades tenha indicado mais de $40 \%$ à exploratória. Isto porque este tipo de estudo remete ao desenvolvimento, ao esclarecimento e ou à modificação de conceitos e de ideias, apresentando menor rigidez no planejamento, e raramente se aplicando quando se trabalha com procedimentos de amostragem e com técnicas quantitativas de coleta de dados - ou seja, contrariamente ao que se dá no caso das pesquisas descritivas. Ora, considerando que a maioria dos estudos da amostra indicou abordagem quantitativa, nota-se aqui um paradoxo, talvez explicável pela falha dos autores em corretamente lhe imputarem a finalidade correta.

Já no que tange aos meios de pesquisa mais utilizados, a primazia da survey confere com a predominância dos trabalhos quantitativos. Também denominado de levantamento de campo, a survey se caracteriza pela interrogação direta das pessoas cujo comportamento se deseja conhecer, selecionando-se amostra significativa delas mediante procedimentos estatísticos.

Por outro lado, a baixa menção ao uso do meio bibliográfico expõe uma falha grave quanto ao entendimento de o que seja um meio de pesquisa. Isto porque, à exceção dos trabalhos baseados na grounded theory, via de regra os artigos científicos contêm referencial teórico usualmente oriundo de fontes secundárias bibliográfico-documentais. Ipso facto eles estarão sempre utilizando pesquisa bibliográfica e ou documental - e, frequentemente, telematizada - como meio.

A técnica de levantamento de dados mais identificada foi o questionário. Isto, de novo, está perfeitamente em linha com a predominância dos estudos quantitativos. O segundo lugar na preferência, ocupado pelas entrevistas, também faz sentido, porque os trabalhos quali-quanti e os puramente qualitativos normalmente utilizam este instrumento para o levantamento de evidências. Por seu turno, o uso do grupo focal, com praticamente $8 \%$ das observações, 
foi uma grata surpresa. Isto porque esta técnica muitas vezes sofre certo repúdio por parte dos autores, tendo em vista as limitações operacionais que o caracterizam, tais como dificuldades para reunir os grupos para as reuniões, a necessidade de haver um moderador capaz e treinado para conduzir o processo, e o fato de os dados coletados poderem apresentar elevado grau de dificuldade de análise.

Finalmente, o mapeamento das formas identificadas de análise dos dados ou das evidências não surpreendeu: a predominância daquelas ligadas à abordagem quantitativa fez sentido. Apenas se deve ressaltar a riqueza da diversidade destas formas, com 18 tipos diferentes, claro indicador da criatividade dos pesquisadores dedicados a esta abordagem, numa evidente busca pelas melhores práticas de comprovarem as hipóteses de seus estudos.

Pelo lado das técnicas utilizadas nas análises qualitativas (puras ou quali-quanti), a dominação das análises de discurso e de conteúdo evidenciou que os pesquisadores se mantêm refratários a alternativas que se prestam a estes estudos, tais como as análises semiótica, de conversação e de gêneros comunicativos. Estas podem contribuir trazendo não só um novo frescor à pesquisa brasileira em Marketing, como também lhe dando - pela via da originalidade - maiores condições de competir tanto nacional quanto internacionalmente.
Devido à restrição amostral à subárea Comportamento do Consumidor da área de Marketing dos EnANPADs de um triênio específico, este estudo apresenta limitações naturais. Uma delas é o impedimento a inferências para outros períodos, assim como para outros eventos. Mesmo assim, entendese que, em termos acadêmicos, esta pesquisa contribuiu positivamente por apontar características metodológicas dos artigos submetidos ao congresso mais importante da área de Administração de Empresas do Brasil.

Para futuros estudos, recomenda-se a ampliação do escopo temporal e a extensão a outras subáreas do campo de Marketing dos EnANPADs.

\section{REFERÊNCIAS BIBLIOGRÁFICAS}

ANPAD - Associação Nacional de PósGraduação e Pesquisa em Administração. Disponível em <www.anpad.org.br>. Acesso em 05 dez 2013

ARAÚJO, C.A. Bibliometria: evolução história e questões atuais. Em Questão, v. 12, n. 1, p. 11-32, jan./jun, 2006.

CERVO, A.; BERVIAN, P.; DA SILVA, R. Metodologia Científica. São Paulo: Pearson, $6^{\mathrm{a}}$ ed., 2013.

COELHO, P.; SILVA, R. Um estudo exploratório sobre as metodologias aplicadas em pesquisas na área de contabilidade no EnANPAD. Revista Contemporânea de Contabilidade, ano 4, v. 1, n. 8, jul-dez, p. 139-159, 2007

COLLIS, J.; HUSSEY, R. Pesquisa em

Administração. 2a . Ed., São Paulo:

Bookman, 2005 
CHURCHILL, G. A.; PETER, J. P.

Marketing: criando valor para o cliente. São Paulo: Saraiva. 2000.

CHURCHILL, G. A.; PETER, J. P. Marketing research: methodological foundations. Oxford: The Dryden Press, $4^{\mathrm{a}}$ ed., 2001.

DEMO, P. Metodologia Científica em

Ciências Sociais. São Paulo: Atlas, 2009

DIAS, Sérgio Roberto. Gestão de

Marketing. São Paulo: Saraiva,2004.

ENGEL, J. F.; KOLLAT, D. T.;

BLACKWELL, R. D. Consumer behavior.

New York: Holt Reinert\& Winston, 1968.

ENGEL, J. F., BLACKWELL, R. D.; MINIARD, P. W. Comportamento do consumidor. Rio de Janeiro: JC. $8^{\mathrm{a}}$ ed., 2000.

FERBER, R.; WALES, H. G. Motivatíon and market behavior. Homewood, Ill: Richard D. Irvin, 1958.

FIGUEIREDO, Nice. Tópicos modernos em Bibliometria. Brasília: Associação dos Bibliotecários do Distrito Federal, 1977.

GIANESI, Irineu G.N., CORRÊA, Henrique Luiz.Administração estratégica de serviços: operações para a satisfação do cliente. 1.ed. - 14.reimpr. - São Paulo: Atlas, 2006.

GIL, A. C. Como Elaborar Projetos de Pesquisa. São Paulo: Atlas, $5^{\text {a }}$ ed., 2010.

GIL, A.C. Métodos e técnicas de pesquisa social. São Paulo: Atlas, $6^{\text {a }}$ ed., 2012.

GONÇALVES, C A.; MEIRELLES, A.M.

Projetos e relatórios de pesquisa em Administração. São Paulo: Atlas, 2004

GUEDES, V.; BORSCHIVER, S.

Bibliometria: uma ferramenta estatística para a gestão da informação e do conhecimento, em sistemas de informação, de comunicação e de avaliação científica e tecnológica. In: VI CINFORM - Encontro Nacional de Ciência da Informação. Anais... 2005, Salvador. Salvador: ICI/UFBA, 2005.

HOLBROOK, M. B. What is consumer reserch? Journal of Consumer Research, v. 14, p. 128-32, June 1987.

HOWARD, J. A. Marketing management analysis and planning. Ed.rev. Homewood, Ill: Richard D. Irwin, 1963.

KATONA, G. The powerful consumer. New York: McGraw-Hill, 1960.

KOTLER, P. Administração de marketing. São Paulo: Atlas. 1998.

KOTLER, P. Administração de marketing: a edição do novo milênio. São Paulo: Prentice Hall, 10ª ed., 2000.

KOTLER, P.; ARMSTRONG, G. Princípios de marketing. Rio de Janeiro: Prentice Hall, $5^{a}$ ed., 1993.

KOTLER, P.; KELLER, K. L.

Administração de marketing. São Paulo: Pearson Prentice Hall, 12 a ed., 2006.

LAKATOS, E. M.; MARCONI, M. A. Fundamentos de metodologia científica. São Paulo: Atlas, 2003.

LAKATOS, Eva Maria; MARCONI, Marina de Andrade. Fundamentos de metodologia científica. São Paulo: Atlas, 2010.

MALHOTRA, N.K. Marketing Research: An Applied Approach. Pearson Education, Limited, $3^{\text {a }}$ ed., 2007.

MARTINS, G.; TEOPHILO, C. Metodologia da Investigação Científica para Ciências Sociais Aplicadas. São Paulo: Atlas, 2009.

MICHEL, M. H. Metodologia e Pesquisa Científica em Ciências Sociais. São Paulo: Atlas, 2009.

MORAIS, P. Impacto do Marketing Digital no sector da Saúde. 2012. Disponível em http://mktmorais.com/category/marketingdigital-sector-saude/. Acesso em $08 \mathrm{dez} 2013$ 
NEWMAN, J. On knowing the consumer.

[S. 1.]: Ronald Press, 1963.

NICHOLAS, David; RITCHIE, Maureen.

Literature and bibliometrics. London: Clive

Bingley, 1978.

PEIRCE, Charles Sanders. Semiótica e

filosofia. São Paulo: Cultrix, Editora

Universidade de São Paulo, 1975.

PRITCHARD, A. Statistical Bibliography ou

bibliometrics? Journal of Documentation,

25(4): 348,349, dez. 1969.

RICHERS, R. (1984). O enigmático mais

indispensável consumidor: teoria e prática.

Revista de Administração, 19(3), 46-56, 1984.

SCHIFFMAN, L. G., \&KANUK, L.

Comportamento do consumidor (6a ed.).

Rio de Janeiro: LTC, 2000.

SHETH, J.N.; MITTAL, B.; NEWMAN, B.I.

Comportamento do cliente: indo além do comportamento de do consumidor. São Paulo: Atlas, 2001.

SANDHUSEN, R L. Marketing Básico. São Paulo: Saraiva, $2^{\mathrm{a}}$ ed., 2003.

SEVERINO, A, J. Metodologia do Trabalho

Científico. São Paulo: Cortez, $23^{\mathrm{a}}$ ed., 2010.

SOLOMON, M. R. (1998). Consumer

behavior: buying, having and being. New

Jersey: Prentice-Hall, 4a ed., 1998.

SOLOMON, M. R. O comportamento do

consumidor: comprando, possuindo e sendo.

Porto Alegre: Bookman, $5^{\text {a }}$ ed., 2002. 